\title{
Competitive abilities of invasive Lagarosiphon major and native Ceratophyllum demersum in monocultures and mixed cultures in relation to experimental sediment dredging
}

\author{
Iris Stiers*, Josphine Njambuya, Ludwig Triest \\ Plant Biology and Nature Management, Vrije Universiteit Brussel, Pleinlaan 2, BE-1050 Brussels, Belgium
}

\section{A R T I C L E I N F O}

\section{Article history:}

Received 11 August 2010

Received in revised form 21 April 2011

Accepted 9 May 2011

Available online 13 June 2011

\section{Keywords:}

Invasive species

Relative growth rate

Competition

Aquatic vegetation management

Aquatic ecosystem

Sediment dredging

\section{Introduction}

Increased worldwide travel and trade has led to the introduction of many invasive plant species beyond their native range (Westphal et al., 2008). The invasion of freshwater ecosystems by highly competitive new species is a global phenomenon with ecological and economic consequences, especially with the high vulnerability of these environments to invasion (Pimentel et al., 2000; Shea and Chesson, 2002; Strayer, 2010). New species interact with native species and competition is one of the most important biotic interactions. Competitive capacity determines the establishment success of newly introduced species as well as resistance to invasion (Lockwood et al., 2007). In aquatic ecosystems, the most intense competition is expected to occur between plants of similar growth form occupying the same position in the water column (Gopal and Goel, 1993).

Invasive Lagarosiphon major (Ridley) Moss and native Ceratophyllum demersum L. occur potentially in similar habitats as they both have a wide ecological range. $L$. major, a rooted, submerged aquatic species native to southern Africa, is recognized as a noxious, invasive aquatic weed in several European countries (DAISIE,

\footnotetext{
* Corresponding author. Tel.: +32 6293726; fax: +32 6293413.

E-mail address: istiers@vub.ac.be (I. Stiers).
}

2009) with few isolated populations in Belgium (Branquart et al., 2009). As observed for most alien Hydrocharitaceae species, this submerged perennial aquatic plant develops dense monospecific stands which often occupy the entire water volume from the bottom to the surface, restrict water movement, cut off light and interfere with recreation activities (McGregor and Gourlay, 2002). L. major has been reported to outcompete native submerged aquatic vegetation (e.g. Charophytes, Myriophyllum spp., Potamogeton spp.) and affect associated assemblages of aquatic invertebrates and vertebrates (Rattray et al., 1994; Keenan et al., 2009). C. demersum is a submerged free-floating species native to Europe and widely distributed in Belgium (Van Landuyt et al., 2006). C. demersum however is considered as a pest in New Zealand, where it has spread rapidly and outcompeted other invasive plants (Wells et al., 1997). Like $L$. major, $C$. demersum has been observed to displace native aquatic vegetation by shading due to the formation of a closed canopy and to present problems in lakes and waterways. Also in its native range $C$. demersum can be locally abundant and dominate entire water bodies. This suggests that both species have a high competitive ability. In Flanders (northern Belgium) we visited three meso-eutrophic ponds (two private ponds: N $51^{\circ} 12^{\prime}$; E $4^{\circ} 40^{\prime}$ and $\mathrm{N} 51^{\circ} 02^{\prime} \mathrm{E} 4^{\circ} 05^{\prime}$; one pond in a nature reserve: $\mathrm{N} 51^{\circ} 01^{\prime}$; E $4^{\circ} 52^{\prime}$ ) where both species co-occur. In the nature reserve $L$. major was the dominant macrophyte with some patches of $C$. demersum. In the two private ponds both species were equally abundant and formed 
dense canopies. Therefore competitive interactions for resources seem inevitable, particularly because both species are canopy forming submerged hydrophytes that inhabit shallow as well as deep littoral habitats (Wells et al., 1997), and can grow in a wide range of aquatic habitats (Vestergaard and Sand-Jensen, 2000; National Heritage Trust, 2003).

Today, many European lakes and ponds suffer from eutrophication as a result of increased agricultural intensification and urbanization, which has led to a considerable accumulation of phosphorus in the sediment. High nutrient loading is thought to increase ecosystem invasibility (Davis et al., 2000) and lend competitive advantage of invasive species relative to native species (Daehler, 2003). In pond ecosystems, sediment dredging has been shown to be a successful restoration measure in reducing internal nutrient load (Søndergaard et al., 2000) and restoring local biodiversity (Louette et al., 2009). However, little is known on how pond restoration by dredging would affect the performance of invasive species relative to native species. Previous studies on the influence of eutrophication on aquatic weeds invasiveness have mainly focused on manipulation of nutrient levels by adding fertilizers (Van et al., 1999; Kercher and Zedler, 2004; Mony et al., 2007; Kennedy et al., 2009).

In the present study, we have investigated experimentally the impact of sediment conditions before and after dredging on the interference competition between $L$. major and C. demersum. We mimicked these conditions by using sediments which were (a) undisturbed with a high amount of organic sediments ('before dredging' treatment) and (b) restored - removal of upper layer with a lower amount of nutrients in the remaining soil ('after dredging' treatment). The objectives were (1) to compare growth of $L$. major and C. demersum and (2) to examine the possible competitive effects between $L$. major and $C$. demersum, both in monocultures and mixed cultures at various planting densities under the two different sediment conditions.

\section{Materials and methods}

\subsection{Experimental design}

The experiment was carried out at the Vrije Universiteit Brussel, Belgium over 7 weeks in July-August 2008. Plants of Ceratophyllum demersum and Lagarosiphon major were collected in a private pond ( $51^{\circ} 12^{\prime}$; E $4^{\circ} 40^{\prime}$ ) where they co-occur and were kept in tap water of $20^{\circ} \mathrm{C}$ for one night before planting. Apical shoot tips, of $10 \mathrm{~cm}$ in length, were deposited without roots and ramifications into $2.5 \mathrm{~L}$ plastic pots ( $18 \mathrm{~cm}$ diameter, $14 \mathrm{~cm}$ deep) filled with sediment (either sediment condition (a) or (b)) to a depth of approximately $5 \mathrm{~cm}$. To avoid soil loss and to stabilize the plants, a $0.5 \mathrm{~cm}$ layer of gravel was placed at the top. The pots were placed in filled $20 \mathrm{~L}$ outdoor plastic tanks $(30 \mathrm{~cm}$ diameter, $31 \mathrm{~cm}$ deep, one pot per tank). Two-thirds of the aquarium water was replaced each other day to reduce the potential for algal growth and to replenish nutrients in the water column. All tanks were randomly rearranged each day to reduce the variation of light climate. Pond sediments and overlying water were collected from the Tenreuken pond ( $\mathrm{N}$ $50^{\circ} 48^{\prime}$; E $4^{\circ} 25^{\prime}$ ), a peri-urban hypereutrophic pond in the Brussels Capital Region where $C$. demersum is the dominant macrophyte (Peretyatko et al., 2007). Intact sediment cores between 30 and $50 \mathrm{~cm}$ long were taken with a hand-held coring tube. Undisturbed cores were used as the 'before dredging' treatment. For mimicking the 'after dredging' treatment, the uppermost $10-15 \mathrm{~cm}$ sediment layer from undisturbed cores was removed. The most essential sediment components of the two sediment types are given in Table 1.

We used a complete additive design (Spitters, 1983) with $L$. major/C. demersum planting densities as $0 / 4 ; 0 / 8 ; 4 / 0 ; 8 / 0 ; 4 / 4$;
Table 1

Main nutrients of the aquarium water (range) and of the two sediment types.

\begin{tabular}{|c|c|c|c|c|c|}
\hline \multicolumn{6}{|l|}{ Water } \\
\hline $\mathrm{TP}\left(\mathrm{mg} \mathrm{Pl}^{-1}\right)$ & \multicolumn{2}{|c|}{$\operatorname{SRP}\left(\mathrm{mg} \mathrm{Pl}^{-1}\right)$} & \multicolumn{2}{|c|}{$\mathrm{NO}_{3}{ }^{-}\left(\mathrm{mg} \mathrm{N}^{-1}\right)$} & $\mathrm{NH}_{4}^{+}\left(\mathrm{mg} \mathrm{Nl}^{-1}\right)$ \\
\hline \multirow[t]{3}{*}{$0.018-0.087$} & \multicolumn{2}{|c|}{$0.001-0.007$} & \multicolumn{2}{|c|}{$0.044-0.139$} & $0.088-0.188$ \\
\hline & \multicolumn{5}{|c|}{ Sediment } \\
\hline & $\mathrm{C}_{\mathrm{org}}(\%)$ & $\mathrm{N}-\mathrm{Kj}($ & $\left.\mathrm{g}^{-1}\right)$ & $\mathrm{P}\left(\mathrm{mg} \mathrm{g}^{-1}\right)$ & $\mathrm{NO}_{3}^{-}\left(\mathrm{mg} \mathrm{Ng}^{-1}\right)$ \\
\hline re dredging & 2.7 & 2.68 & & 0.12 & 0.028 \\
\hline r dredging & 2.7 & 2.28 & & 0.10 & 0.006 \\
\hline
\end{tabular}

Abbreviations: SRP, soluble reactive phosphorus; TP, total phosphorus; N-Kj, Kjeldah nitrogen; $C_{\text {org }}$, organic carbon.

8/8; 4/8 and 8/4 plants per pot (following Barrat-Segretain and Elger (2004)). Each density had four replicates. Monocultures and mixed cultures of $L$. major and $C$. demersum were grown for seven weeks. The mean individual plant dry weight measured at the start of the experiment ( 20 stem apices of $10 \mathrm{~cm}$ length for each species) after drying at $70^{\circ} \mathrm{C}$ for $48 \mathrm{~h}$ was $0.180 \pm 0.012 \mathrm{~g}$ (mean $\pm \mathrm{SE}$ ) for L. major and $0.140 \pm 0.009 \mathrm{~g}$ (mean $\pm \mathrm{SE}$ ) for $C$. demersum. Two weeks after the start of the experiment the plants of both species were established. From this date (week 3 =sampling week 1), the total cumulative length of four plants (including ramifications) of each species in each tank was measured weekly. At the end of week seven, all the plants were harvested, the number of roots was counted and the plants were dried at $70^{\circ} \mathrm{C}$ for $48 \mathrm{~h}$. The dry weight of shoots, roots and whole plants (all g plant ${ }^{-1}$ ) was measured. Water temperature (range $20.3-26.0^{\circ} \mathrm{C}$ ), $\mathrm{pH}$ (range 7.00-9.71) and light intensity ( $2 \mathrm{~cm}$ under water surface, range $882-3615 \mu \mathrm{mol} \mathrm{m}^{-2} \mathrm{~s}^{-1}$ PAR) were measured weekly. Chemical characteristics of the aquarium water were measured at weeks 3 , 5 and 7 and revealed meso- to eutrophic conditions (UNEP, 1999) (Table 1).

\subsection{Statistical analysis}

The relative growth rate (RGR) of the two species was calculated at the end of the experiment by the formula $\mathrm{RGR}=\left(\ln X_{2}-\ln X_{1}\right) /\left(t_{2}-t_{1}\right)$, where $X_{1}$ and $X_{2}$ are the plant mean length $(L)$ or plant dry weight $(W)$ at time $t_{1}$ and $t_{2}$, respectively (Hunt, 1990). Before all statistical analyses, data were log-transformed if required to ensure normality and homogeneity of variance (Sokal and Rohlf, 2003).

The difference between the growth curves of the two species and between treatments within species was tested with ANCOVA with sampling week as covariate and species and pond management condition as fixed factors. The different RGR mean values were compared using $t$-tests or ANOVA (followed by Tukey post-hoc tests after significant ANOVA).

Competitive abilities of each species were estimated using the reciprocal yield model (Spitters, 1983). This procedure uses linear multiple regressions of the form:

$\frac{1}{X_{\mathrm{L}}}=b_{\mathrm{LO}}+b_{\mathrm{LL}} N_{\mathrm{L}}+b_{\mathrm{LC}} N_{\mathrm{C}}$

$\frac{1}{X_{\mathrm{C}}}=b_{\mathrm{C} 0}+b_{\mathrm{CC}} N_{\mathrm{C}}+b_{\mathrm{CL}} N_{\mathrm{L}}$

where $X_{\mathrm{L}}$ and $X_{\mathrm{C}}$ are the mean length or mean dry weight per plant and $N_{\mathrm{L}}$ and $N_{\mathrm{C}}$ are densities of $L$. major and $C$. demersum, respectively. The intercepts $\left(b_{\mathrm{L} 0}\right.$ and $b_{\mathrm{C} 0}$ ) estimate the reciprocal of the maximum weight of individual plants. The regression coefficients $b_{\mathrm{CC}}$ and $b_{\mathrm{LL}}$ are measures of intraspecific competition, while $b_{\mathrm{LC}}$ and $b_{\mathrm{CL}}$ measure interspecific competition in mixed cultures. In 

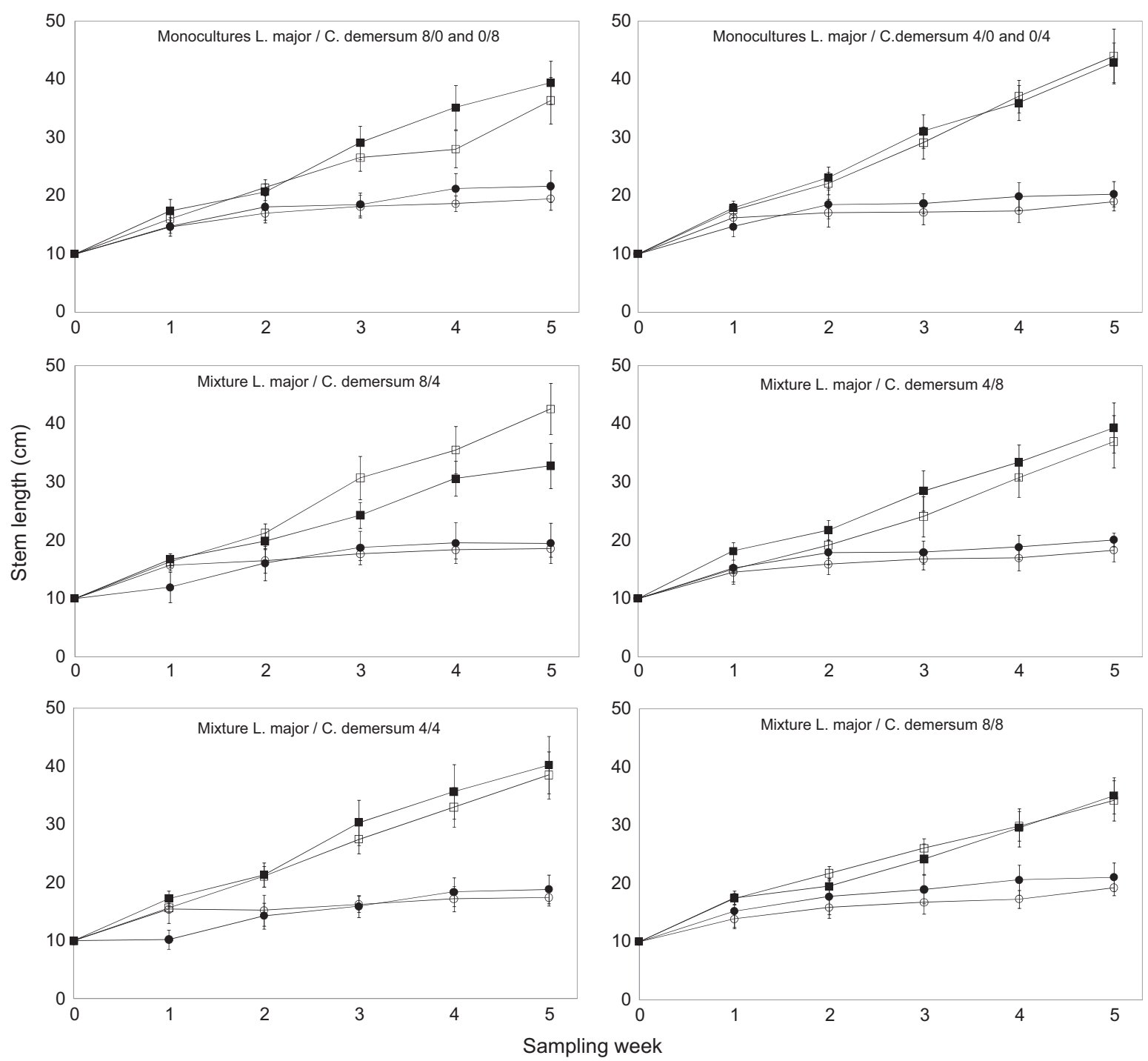

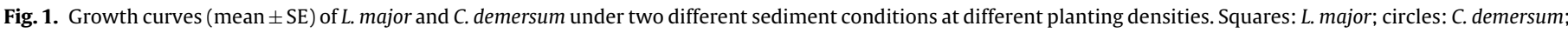
filled symbols: 'before dredging' treatment; open symbols: 'after dredging' treatment.

two species mixed cultures, the coefficients provide quantitative estimates of the reduction in growth of an individual of species 1 due to the addition of individuals of species 1 or species 2 . The significance of these coefficients was tested with F-tests. All analyses were performed using STATISTICA v8.

\section{Results}

\subsection{Stem elongation and biomass}

In all experimental conditions the stem length of $C$. demersum was significantly lower than the stem length of $L$. major (ANCOVA, $P<0.001$, Fig. 1), and for each species the sediment condition had no effect on the stem elongation. $L$. major reached the water surface within a week, then started to grow laterally and formed a canopy near the surface, while $C$. demersum stayed subsurface. Twoway ANOVA showed that the significant difference in stem length between the two species increased with time in monocultures and mixed cultures (significant effect of sampling week $\times$ species interaction, $P<0.001)$.

Averaged across all planting densities, L. major accumulated significantly more total biomass (mean $\pm \mathrm{SE}$ ) compared to $C$. demersum under the 'after dredging' treatment $\left(0.91 \pm 0.04\right.$ g plant $^{-1}$ versus
$0.49 \pm 0.06$ g plant $\left.^{-1}, P<0.001\right)$ as well as under the "before dredging' treatment $\left(0.67 \pm 0.03 \mathrm{~g} \mathrm{plant}^{-1}\right.$ versus $0.37 \pm 0.05 \mathrm{~g} \mathrm{plant}^{-1}$, $P<0.001)$. Mean individual shoot biomass $( \pm \mathrm{SE})$ of $L$. major was higher under the 'after dredging' treatment than under the 'before dredging' treatment $\left(0.78 \pm 0.03 \mathrm{~g} \mathrm{plant}^{-1}\right.$ versus $0.54 \pm 0.02$ g plant $^{-1}, P<0.001$ ), while mean individual root mass and number of roots did not change. For $C$. demersum there was no significant difference in accumulated biomass for the two sediment conditions.

\subsection{Relative growth rate (RGR)}

The RGR based on length of $L$. major was significantly higher than the length RGR of $C$. demersum both in monocultures and mixed cultures at the different densities under both sediment conditions (Fig. 2a). A comparison between the before and after dredging treatment indicate that neither species length RGR were influenced by sediment condition. The small variations in length RGR of both L. major and $C$. demersum plants when comparing monocultures versus mixed cultures were not significant (Fig. 2a).

The RGR based on weight of the two species calculated after seven weeks in monoculture did not differ significantly, but L. major had a significantly higher weight RGR than $C$. demersum in the 


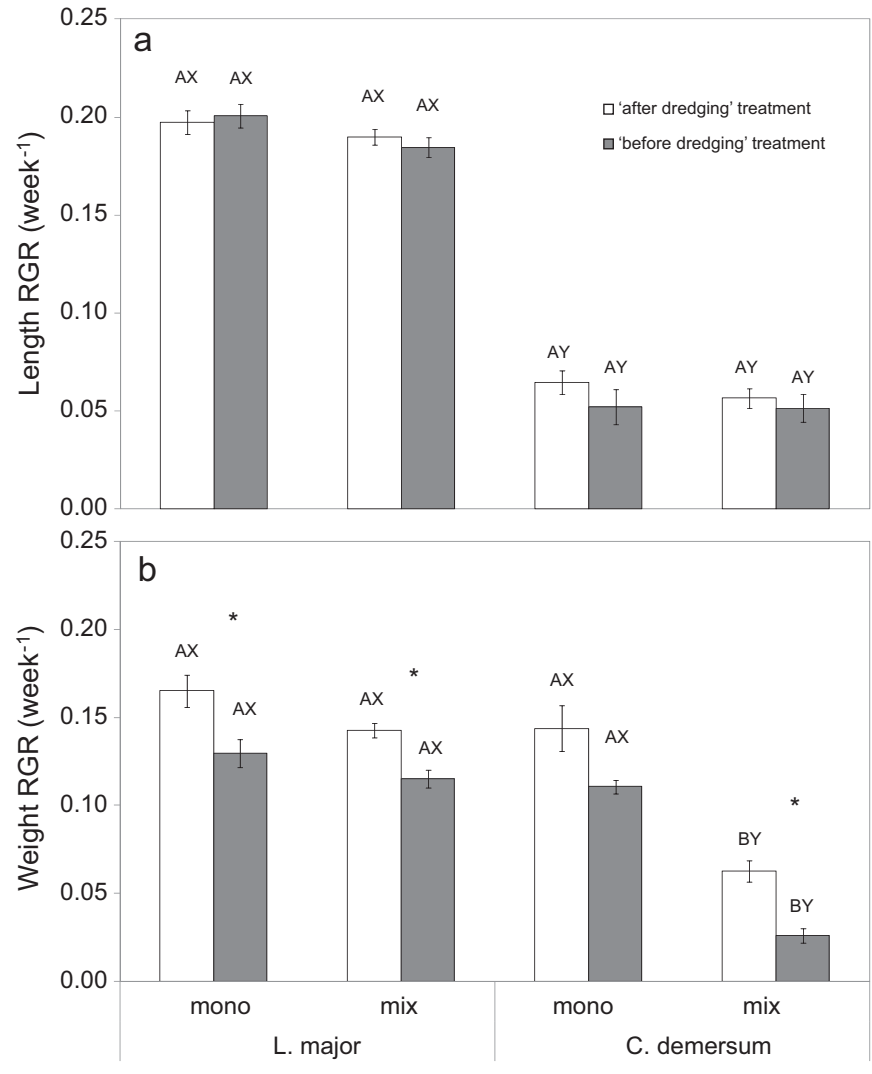

Fig. 2. The mean $R G R \pm S E$ (week ${ }^{-1}$ ) based on (a) total length and (b) dry weight of $L$. major and $C$. demersum cultivated in monocultures and mixed cultures under two different sediment conditions. Data were pooled for L. major:C. demersum mono planting densities and mixed planting densities at each sediment condition, respectively. Statistical differences are indicated by the following symbols: * $(L$. major plants or $C$. demersum plants, grown under the two different sediment conditions); $\mathrm{A}$ and $\mathrm{B}$ (L. major plants or $C$. demersum plants, grown in monocultures versus mixed cultures); $X$ and $Y$ (L. major plants versus C. demersum plants, grown in monocultures and mixed cultures, respectively).

mixed cultures with plants at different densities (Fig. 2b). The different sediment conditions influenced the weight RGR, especially for $L$. major. The weight RGR of $L$. major plants was significantly higher in the 'after dredging' treatment both in monocultures $(P<0.05)$ and mixed cultures $(P<0.001)$. For $C$. demersum this was only the case in the mixed cultures (Fig. 2b). A comparison of the weight RGR between monocultures and mixed cultures indicate that $C$. demersum performed better when growing with a conspecific than a heterospecific neighbour in both sediment conditions $(P<0.001)$. For $L$. major no significant difference between monocultures and mixed cultures was found.

\subsection{Inter- and intraspecific effects (Spitters model)}

Under the 'after dredging' treatment, analysis following Spitters model calculated on dry weight indicated reduced growth due to intraspecific interactions for both species $(P<0.001)$ :

$\frac{1}{W_{\mathrm{L}}}=0.606+0.083 N_{\mathrm{L}}+0.024 N_{\mathrm{C}}, \quad R^{2}=0.67$

$\frac{1}{W_{\mathrm{C}}}=1.307+0.430 N_{\mathrm{C}}-0.042 N_{\mathrm{L}}, \quad R^{2}=0.57$

For L. major (Eq. (1)), the ratio of the coefficients comparing the intensity of intraspecific to interspecific interactions $\left(b_{\mathrm{LL}} / b_{\mathrm{LC}}\right)$ was 3.5. When excluding interspecific competition the $R^{2}$ only declines to 0.62 . This confirms that intraspecific competition from other $L$. major plants was more important than interspecific competition from $C$. demersum plants in mixed cultures. The addition of one $L$. major plant to the mixture reduces the mean $L$. major weight to the same extent as 3.5 C. demersum plants. This is interpreted to mean that, L. major is 3.5 times stronger a competitor that C. demersum.

For $C$. demersum (Eq. (2)), the ratio of the species intra- and interspecific effects $\left(b_{\mathrm{CC}} / b_{\mathrm{CL}}\right)$ was 10.2 indicating that one $C$. demersum plant and $10.2 \mathrm{~L}$. major plants would have the same impact on $C$. demersum average plant weight. When excluding interspecific competition the $R^{2}$ only declines to 0.56 . Hence, for both species the intraspecific competition is greater than the interspecific competition, so they are only partly limited by the same resource or they partly avoid each other. This is interpreted as niche separation (Spitters, 1983). In general, there is niche differentiation when the double quotient $\left(b_{\mathrm{LL}} / b_{\mathrm{LC}}\right) /\left(b_{\mathrm{CL}} / b_{\mathrm{CC}}\right)$ exceeds unity. In this case, we obtained a value of 35.7.

Interspecific interactions had a smaller effect on the competition outcome as we detected only a small change in $R^{2}$ when excluding interspecific competition and some marginally significant interspecific interactions $(0.05<P<0.1)$ of $L$. major on both length and weight of $C$. demersum in the 'before dredging' treatment. Other multiple regressions showed no significant competitive effect for either species.

\section{Discussion}

The co-occurrence of the invasive $L$. major and the native C. demersum is expected to lead to competitive interactions for resources, particularly because both species are canopy forming submerged hydrophytes that inhabit shallow as well as deep littoral habitats (Wells et al., 1997), and can occupy a wide range of aquatic habitats (Vestergaard and Sand-Jensen, 2000; National Heritage Trust, 2003). We have investigated the effect of a common management practice against eutrophication in shallow waters on the performance of invasive species relative to native species. The new species $L$. major possesses traits that classify it as a 'good invader' such as vegetative growth habit, broad environmental tolerance and high relative growth rate (Sutherland, 2004). Due to its high RGR, L. major develops a dense canopy near the surface, which enables it to shade and overgrow co-occurring, lower stature species (Hofstra et al., 1999). Rattray et al. (1994) showed that $L$. major has a greater ability to increase both height and biomass during the initial colonization phase than native Myriophyllum triphyllum. These findings are confirmed by our results which show that, compared with the native species $C$. demersum, the stem elongation and length RGR of $L$. major are twice as high, both in monocultures and mixed cultures and in both sediment conditions; even when initial abundance of $L$. major is low (e.g. mix 4/8). Furthermore, this species has high light requirements so it is advantageous to allocate more resources to length growth. In this experiment the length RGR of $L$. major is higher than the weight RGR, which supports the theory that $L$. major growth resources are channeled to shoot extension (Rattray et al., 1994). However length RGR of both species in this experiment is lower compared to other studies. Our plants have length RGR values between 0.17 and 0.21 week $^{-1}$ for $L$. major and between 0.04 and 0.07 week $^{-1}$ for $C$. demersum, lower than those found by Best and Meulemans (1979) (up to 0.31 week $^{-1}$ ), by Larson (2007) (up to $0.09 \mathrm{day}^{-1}$ ) for C. demersum and by James et al. (2006) $\left(0.063\right.$ day $\left.^{-1}\right)$ for $L$. major. This difference in growth rate may be due to the experimental conditions: any treatment used for manipulating the plants can be a potential stress factor to the plants and cause loss of vitality. This phenomenon was also observed by Larson (2007) for Ranunculus circinatus and by Angelstein et al. (2009) for Myriophyllum spicatum. Another possible explanation is the maximum $\mathrm{pH}$ value recorded in our experiment (up to 10). High pH can cease net pos- 
itive photosynthesis (Allen and Spence, 1981; James et al., 1999) consequently affecting growth and this may explain the lower RGR values observed. Initial plant density has also been reported to influence the growth (Barrat-Segretain and Elger, 2004). The high initial plant density in this study (160-640 plants $\mathrm{m}^{-2}$ ) can therefore have caused the lower growth rates. No differences are observed between the two species for the RGR calculated on weight when they are grown in monocultures for both sediment conditions. This might be explained by the ability of $C$. demersum to grow at relatively low light intensities (Wells et al., 1997) and therefore is expected to produce short, dense shoots under the water surface with an equal weight to the long, thin shoots of $L$. major. The RGR based on weight for $C$. demersum in the monocultures $\left(0.10-0.17\right.$ week $\left.^{-1}\right)$ is similar with what was reported by Larson (2007) $\left(0.02 \mathrm{day}^{-1}\right)$. We could not find comparable values for $L$. major but the weight RGR observed in this experiment (0.10-0.19 week $\left.^{-1}\right)$ was similar with the growth rates reported by Angelstein et al. (2009) for Elodea nuttalli $\left(\sim 0.03\right.$ day $\left.^{-1}\right)$ but lower than what was reported by Barrat-Segretain and Elger (2004) for this species $\left(\sim 0.28\right.$ day $\left.^{-1}\right)$.

When examining the inter- and intraspecific competition using the model of Spitters, we find strong intraspecific effects for the 'after dredging' treatment for RGR calculated on weight. This indicates an effect of the species' initial density on its own biomass, suggesting a separate niche for this species. These results imply that instead of competitive exclusion, coexistence is favoured. Several traits of the studied species support the niche separation theory by Chambers and Prepas (1990) who concluded that interspecific competition plays a minor role in structuring submerged plant communities and that the species coexistence is due to differential utilization of resources (niche separation). First, because of lack of true roots, nutrient uptake by $C$. demersum is almost entirely foliar (Denny, 1972), while for rooted macrophytes (such as L. major) sediments can be the main source of both phosphorus and nitrogen (Barko and Smart, 1980). Second, L. major grows best under conditions of high light intensity (National Heritage Trust, 2003), while $C$. demersum is classified as a shade-adapted species (Wells et al., 1997). A strong intraspecific competition effect and niche differentiation have been reported in other competition experiments. Barrat-Segretain and Elger (2004) found a higher sensitivity to intraspecific neighbours for Elodea canadensis, probably due to competition for some micro-elements. Similarly, Njambuya et al. (2011) found stronger intra- than interspecific interferences in a competition experiment conducted with Lemna species. However, other studies reported equal or stronger interspecific effects (Aguiar et al., 2001; Huckle et al., 2002; Spencer and Rejmánek, 2010). Another explanation, besides niche partitioning, is that light and nutrients of the water column are not limiting. The experiment was conducted in full summer with mean high light intensity measures and chemical analyses of the water showed no decrease of $\mathrm{N}$ and P nutrients during the experiment.

Although there is little evidence for interspecific competition, the growth of $C$. demersum in the mixed cultures is significantly reduced in both sediment conditions. The negative effect of $L$. major on the growth of $C$. demersum in the mixed cultures can be attributed to elevations of the $\mathrm{pH}$ by L. major. Many eutrophic waters have $\mathrm{pH}$ values in the range of $7-8$, where the concentration of free $\mathrm{CO}_{2}$ for photosynthetic activity becomes limiting (Kalff, 2002). A mechanism that enables species to overcome such limiting conditions will provide an aquatic plant with an advantage in alkaline waters. One such mechanism is the efficient utilization of bicarbonate ions as a dissolved inorganic carbon source, which has been described for other Hydrocharitaceae (e.g. Elodea sp.) (Prins et al., 1979). Macrophytes adapted to utilize bicarbonate are able to raise $\mathrm{pH}$ to 10 (O'Sullivan and Reynolds, 2004). In this experiment, photosynthesis by $L$. major raises the $\mathrm{pH}$ to values of almost
10 at the water surface. The limit is 10.4 for bicarbonate uptake. Furthermore, a calcium carbonate marl was formed rapidly on the upper surface of the leaves of L. major (I. Stiers, personal observation), a consequence of bicarbonate uptake by plants (Kalff, 2002). In a study conducted by James et al. (1999), L. major was reported to have the ability to photosynthesize and grow under very stressful conditions of high $\mathrm{pH}$ and low free $\mathrm{CO}_{2}$, perhaps due to more efficient bicarbonate utilization than other species. It seems that this feature is the key to its success in dominating mixed plant communities as prolonged periods of high $\mathrm{pH}$ will suppress the photosynthetic performance of less aggressive submerged macrophytes.

Sediment dredging as a restoration technique is usually performed in shallow water bodies that suffer from internal phosphorus loading, need water deepening, require removal of toxic material and have excessive plant growth (Peterson, 1982). Several studies indicate that sediment removal is successful in the first three cases (Hovenkamp-Obbema and Fieggen, 1992; Van der Does et al., 1992; Søndergaard et al., 2000; Mackie et al., 2007), but the effectiveness of dredging to control aquatic plants has not been well documented. Dredging removes aquatic plants and thereby reduces aquatic weed problems, however, their re-invasion rate will depend on a combination of depth, light, sediment texture and sediment nutrient content (Barko and Smart, 1986; Lauridsen et al., 1993). In our study, the experimental sediment dredging only has a small effect on lowering the nutrient level probably because the thickness of the nutrient-rich top layer that we removed was limited. However, L. major performs better in the 'after dredging' treatment which is lower in nutrients. The species accumulates more total biomass and a higher weight RGR both in monocultures and mixed cultures. Lauridsen et al. (1993) showed that the influence of sediments on growth of submerged aquatic plants might be due to physical properties rather than chemical composition. In our experiment, the top layer, used for the 'before dredging' treatment, consisted of a dark unconsolidated fluid mud layer containing finegrained material. L. major has been reported to be favoured by sandy soil (National Heritage Trust, 2003). The sediment used to simulate the 'after dredging' conditions may have been more favourable for the initial anchoring and hence lead to a more successful growth of $L$. major. This may explain the better performance in the 'after dredging' condition (lower nutrient) relative to 'before dredging' condition (higher nutrient). For $C$. demersum it is not clear why there is a reduced weight RGR in the 'before dredging' treatment in the mixed cultures as this species does not depend on sediment for anchoring or nutrient uptake. A possible explanation can be differences in net diffusion into the overlaying water.

Based on the results of this experimental study, sediment dredging would not be a solution to reduce performance of invasive L. major. Although experimental studies are an important and essential method for interpreting and understanding species performance, they might represent an over-simplification of reality, which limits the ability to extrapolate the results to natural ecosystems. Therefore, care has to be taken when using experimental results for management decisions and the monitoring of the effects of management practices in natural conditions is essential to gain full knowledge on the ecology and performance of invasive exotic species.

\section{Acknowledgements}

We would like to thank K. Coussement, R. De Schutter and T. Driessens for logistic assistance. The editor Prof. Dr. Jan Vermaat, and two anonymous reviewers provided very helpful critiques on an earlier draft of the paper. This paper is part of the 'ALIEN IMPACT' project, funded by the Belgian Science Policy with contract number 
SD/BD/01A and by the Vrije Universiteit Brussel (OZR 1623 BOF, OZR 1946 BOF).

\section{References}

Aguiar, M.R., Lauenroth, W.K., Peters, D.P., 2001. Intensity of intra- and interspecific competition in coexisting shortgrass species. J. Ecol. 89, 40-44.

Allen, H.L., Spence, D.H.N., 1981. The differential ability of aquatic plants to utilize the inorganic carbon supply in freshwaters. New Phytol. 87, 269-283.

Angelstein, S., Wolfram, C., Rahn, K., Kiwel, U., Frimel, S., Merbach, I., Schubert, H., 2009. The influence of different sediment nutrient contents on growth and competition of Elodea nuttalli and Myriophyllum spicatum in nutrient-poor waters. Fundam. Appl. Limnol. Arch. Hydrobiol. 175 (1), 49-57.

Barrat-Segretain, M.-H., Elger, A., 2004. Experiments on growth interactions between two invasive macrophyte species. J. Veg. Sci. 15, 109-114.

Barko, J.W., Smart, R.M., 1980. Mobilization of sediment phosphorus by submerged freshwater macrophytes. Freshwater Biol. 10, 229-238.

Barko, J.W., Smart, R.M., 1986. Sediment-related mechanisms of growth limitation in submersed macrophytes. Ecology 67, 1328-1340.

Best, E.P.H., Meulemans, J.T., 1979. Photosynthesis in relation to growth and dormancy in Ceratophyllum demersum. Aquat. Bot. 6, 53-66.

Branquart, E., Verreycken, H., Vanderhoeven, S., Van Rossum, F., other members of the Belgian Forum on Invasive Species, 2009. ISEIA, a Belgian non-native species assessment protocol. In: Segers, H., Branquart, E. (Eds.), Belgian Biodiversity Platform: Proceedings of a Scientific Meeting on Invasive Alien Species.

Chambers, P.A., Prepas, E.E., 1990. Competition and coexistence in submerged aquatic plant communities: the effects of species interactions versus abiotic factors. Freshwater Biol. 23, 541-550.

Daehler, C.C., 2003. Performance comparisons of co-occurring native and alien invasive plants: implications for conservation and restoration. Annu. Rev. Ecol. Evol. Syst. 34, 183-211.

DAISIE, 2009. Handbook of Alien Species in Europe. Springer, Dordrecht.

Denny, P., 1972. Sites of nutrient absorption in aquatic macrophytes. J. Ecol. 60, 819-829.

Davis, M.A., Grime, J.P., Thompson, K., 2000. Fluctuating resources in plant communities: a general theory of invasibility. J. Ecol. 88, 528-534.

Gopal, B., Goel, U., 1993. Competition and allelopathy in aquatic plant communities. Bot. Rev. 59, 155-210.

Hofstra, D.E., Clayton, J., Green, J.D., Auger, M., 1999. Competitive performance of Hydrilla verticillata in New Zealand. Aquat. Bot. 63, 305-324.

Hovenkamp-Obbema, I.R.M., Fieggen, W., 1992. The effects of dredging and fish stocking on the trophic status of shallow, peaty ditches. Hydrobiologia 233, 225-233.

Huckle, J.M., Marrs, R.H., Potter, J.A., 2002. Interspecific and intraspecific interactions between salt marsh plants: integrating the effects of environmental factors and density on plant performance. Oikos 96, 307-319.

Hunt, R., 1990. Basic Growth Analysis. Unwin Hyman, London, UK.

James, C.S., Eaton, J.W., Hardwick, K., 1999. Competition between three submerged macrophytes, Elodea canadensis Michx, Elodea nuttalli (Planch.) St John and Lagarosiphon major (Ridl.) Moss. Hydrobiologia 415, 35-40.

James, C.S., Eaton, J.W., Hardwick, K., 2006. Responses of three invasive aquatic macrophytes to nutrient enrichment do not explain their observed field displacements. Aquat. Bot. 84, 347-353.

Kalff, J., 2002. Limnology: Inland Water Ecosystems. Prentice-Hall, Inc., USA.

Keenan, E., Baars, J.-R., Caffrey, J.M., 2009. Changes in littoral invertebrate communities in Lough Corrib in response to an invasion by Lagarosiphon major. In: Pieterse, A., Rytkönen, A.-M., Hellsten, S. (Eds.), Proceedings of the 12th EWRS International Symposium on Aquatic Weeds.

Kennedy, T.L., Horth, L.A., Carr, D.E., 2009. The effects of nitrate loading on the invasive macrophyte Hydrilla verticillata and two common, native macrophytes in Florida. Aquat. Bot. 91, 253-256.

Kercher, S.M., Zedler, J.B., 2004. Multiple disturbances accelerate invasion of reed canary grass (Phalaris arundinacea L.) in a mesocosm study. Oecologia 138, 455-464.

Larson, D., 2007. Growth of three submerged plants below different densities of Nymphoides peltata (SG. Gmel.) Kuntze. Aquat. Bot. 86, 280-284.
Lauridsen, T.L., Jeppesen, E., Andersen, F.O., 1993. Colonization of submerged macrophytes in shallow fish manipulated Lake Vaeng: impact of sediment composition and waterfowl grazing. Aquat. Bot. 46, 1-15.

Lockwood, J.L., Hoopes, M.F., Marchetti, M.P., 2007. Invasion Ecology. Blackwell Publishing, UK.

Louette, G., Declerck, S., Vandekerkhove, J., De Meester, L., 2009. Evaluation of restoration measures in a shallow lake through a comparison of present day zooplankton communities with historical samples. Restor. Ecol. 19, 629-640.

Mackie, J.A., Natali, S.M., Levinton, J.S., Sanudo-Wilhelmy, S.A., 2007. Declining meta levels at foundry cove (Hudson river New York): response to localized dredging of contaminated sediments. Environ. Pollut. 149, 141-148.

McGregor, P., Gourlay, H., 2002. Assessing the prospects for biological control of Lagarosiphon (Lagarosiphon major (Hydrocharitaceae)). DOC Science Interna Series 57, Department of Conservation, Wellington, New Zealand.

Mony, C., Koschnick, T.J., Haller, W.T., Muller, S., 2007. Competition between two invasive Hydrocharitaceae (Hydrilla verticillata (L.f.) (Royle) and Egeria densa (Planch)) as influenced by sediment fertility and season. Aquat. Bot. 86, 236-242.

National Heritage Trust, 2003. Lagarosiphon - Lagarosiphon major. Weed Management Guide.

Njambuya, J., Stiers, I., Triest, L., 2011. Competition between Lemna minuta and Lemna minor at different nutrient concentrations. Aquat. Bot. 94, 158-164.

O'Sullivan, P.E., Reynolds, C.S., 2004. The lakes handbook. Limnology and limnetic ecology, vol. 1. Blackwell Publishing, Oxford, 699 pp.

Peretyatko, A., Teissier, S., Symoens, J.-J., Triest, L., 2007. Phytoplankon biomass and environmental factors over a gradient of clear to turbid peri-urban ponds. Aquat. Conserv. Mar. Freshwater Ecosyst. 17, 584-601.

Peterson, S.A., 1982. Lake restoration by sediment removal. Water Res. Bull. 18 423-435

Pimentel, D., Lach, L., Zuniga, R., Morrison, D., 2000. Environmental and economic costs of nonindigenous species in the United States. Bioscience 50, 53-65.

Prins, H.B.A., Snel, J.F.H., Helder, R.J., Zanstra, P.E., 1979. Photosynthetic bicarbonate utilization in the aquatic angiosperms Potamogeton and Elodea. Hydrobiol. Bull. $13,106-111$.

Rattray, M.R., Howard-Williams, C., Brown, J.M.A., 1994. Rates of early growth of propagules of Lagarosiphon major and Myriophyllum triphyllum in lakes of differing trophic status. N. Z. J. Mar. Freshwater Res. 28, 235-241.

Shea, K., Chesson, P., 2002. Community ecology theory as a framework for biological invasions. Trends Ecol. Evol. 17, 170-176.

Sokal, R.R., Rohlf, F.J., 2003. Biometry: The Principles and Practice of Statistics in Biological Research. W.H. Freeman and Company, New York.

Søndergaard, M., Jeppesen, E., Jensen, P.J., Lauridsen, T., 2000. Lake restoration in Denmark. Lake Reservoir Manage. 5, 151-159.

Spencer, D.F., Rejmánek, M., 2010. Competition between two submersed aquatic macrophytes Potamogeton pectinatus and Potamogeton gramineus, across a light gradient. Aquat. Bot. 92, 239-244.

Spitters, C.J.T., 1983. An alternative approach to the analysis of mixed cropping experiments. 1. Estimation of competition effects. Neth. J. Agric. Sci. 31, 1-11.

Strayer, D.L., 2010. Alien species in fresh waters: ecological effects, interactions with other stressors, and prospects for the future. Freshwater Biol. 55, 152-174.

Sutherland, S., 2004. What makes a weed a weed: life history traits of native and exotic plants in the USA. Oecologia 141, 24-39.

UNEP (United Nations Environment Program), 1999. Planning and management of lakes and reservoirs: an integrated approach to eutrophication, Technical Publication Series 11, Shiga, Japan.

Van, T.K., Wheeler, G.S., Center, T.D., 1999. Competition between Hydrilla verticillata and Vallisneria americana as influenced by soil fertility. Aquat. Bot. 62, 225-233.

Van der Does, J., Verstraelen, P., Boers, P., Van Roestel, J., Roijackers, R., Moser, G., 1992. Lake restoration with and without dredging of phosphorus-enriched upper sediment layers. Hydrobiologia 233, 197-210.

Van Landuyt, W. Hoste, I., Vanhecke, L., Van den Bremt, P., Vercruysse, E., De Beer, D., 2006. Atlas van de Flora van Vlaanderen en het Brussels Gewest. Instituut voor Natuur- en Bosonderzoek en Nationale Plantentuin van België, Brussel.

Vestergaard, O., Sand-Jensen, K., 2000. Alkalinity and trophic state regulate aquatic plant distribution in Danish Lakes. Aquat. Bot. 67, 85-107.

Wells, R.D.S., De Winton, M.D., Clayton, J.S., 1997. Successive macrophyte invasions within the submerged flora of Lake Tarawera, Central North Island New Zealand. N. Z. J. Mar. Freshwater Res. 31, 449-459.

Westphal, M.I., Browne, M., MacKinnon, K., Noble, I., 2008. The link between international trade and the global distribution of invasive alien species. Biol. Invas. 10, 391-398. 